\title{
Understanding visuals in HIV/AIDS education in South Africa : differences between literate and low-literate audiences
}

\author{
Adelia Carstens $^{1 *}$, Alfons Maes ${ }^{2}$ and Lilian Gangla-Birir ${ }^{3}$ \\ 1 Unit for Academic Literacy, University of Pretoria, Lynnwood Road, Hatfield, Pretoria 0002, \\ South Africa \\ 2 Tilburg University, Warandelaan 2, PO Box 90153, 5000 LE Tilburg, The Netherlands \\ 3 University of the Free State, PO Box 339, Bloemfontein 9300, South Africa \\ * Corresponding author, e-mail: adelia.carstens@up.ac.za
}

This article reports on a research project aimed at determining the scope and nature of differences in picture comprehension between literate and low-literate audiences in the context of HIV and AIDS. Structured interviews were held with $\mathbf{3 0}$ low-literate and 24 literate adult speakers of African languages. The responses were coded and analysed both qualitatively and quantitatively. Consistent with previous research, we found that purely analogical visuals pose relatively few interpretation problems across the literacy spectrum. Literate and low-literate respondents recognised human beings and familiar analogous objects equally successfully. The interpretation of abstract items was problematic for respondents at both literacy levels, but relatively more so for low-literate respondents. Purely symbolic or conventional abstract elements, such as speech and thought balloons, and purely mathematical symbols are difficult for low-literate individuals since they do not have any analogical residue that will trigger relevant meaning aspects of the visual. Metaphors are difficult when they require culture-specific knowledge. The results strongly suggest that designers should exploit the expressive power of the human body in constructing (abstract) meaning. All humans have comparable experiences with associated basic actions and bodily expressions. Therefore, facial expressions and body postures and positions are powerful in transferring complex messages. We advise that pictorial metaphors, art styles that distort objects, complex pictures with partially symbolic content, as well as abstract symbols borrowed from written language should be omitted where possible.

Keywords: abstract meaning, analogical visuals, symbolic visuals, pictorial metaphor, picture comprehension

\section{Using visuals to promote HIV education for lowliterate1 audiences}

Effective communication is essential for health promotion and disease prevention. People need to understand health information to apply it to their own behaviour. Davis, Crouch, Wills, Miller \& Abdehou (1990) regard comprehension as the most important of the literacy skills used in healthcare. These authors found in their research in the United States that the average reading comprehension of public clinic patients was at the 6th-grade level, whereas most tested materials for patient-education required an 11th- to 14th-grade reading level. Forty percent of the public clinic patients tested were reading below a 5th-grade level and could be considered 'severely illiterate' (see Plimpton \& Root, 1994).

The situation in South Africa is comparable. Basic instructional materials on health issues (including HIV and AIDS) have a readability level of just below 60, which is equivalent to Grade 9 (Carstens \& Snyman, 2003), while more than $70 \%$ of the South African population have only marginal reading skills: $30 \%$ are functionally illiterate and 40\% have limited skills (Carstens, 2004; Project Literacy, 2004). A compounding factor is that, as a rule, $30-50 \%$ of low-literate patients read three to five years below their educational level (Davis et al., 1990). Moreover, the grade reported by low-literate audiences is often adjusted upward by a few levels, presumably to save face. 
Formal education is one of the most important socioeconomic correlates of good health in adult populations (Grosse \& Auffrey, 1989). The most poorly educated adults, those with the lowest literacy levels, suffer the highest rates of morbidity and mortality from chronic diseases and conditions (National Work Group on Literacy and Health, 1989; Plimpton \& Root, 1994; Rudd, Moeykens \& Colton, (1999). One reason for this correlation is that if people cannot understand available healthcare information, they are unable to improve their health by changing potentially harmful behaviours.

In developing countries such as South Africa, where almost two-thirds of the population cannot read basic health-education materials, a solution is often sought through visual media (Arbuckle, 2004). In health campaigns across the world visuals are used where the written word fails to communicate effectively - usually to supplement, extend or reinforce oral instructions (see Doak, Doak \& Root, 1996; Mayeaux, Murphy, Arnold, Davis, Jackson \& Sentell, 1996). Moreover, various studies report on the successes of using visuals in health education in developing countries (see Tomaselli \& Tomaselli, 1984; Zimmermann, 1982; Plimpton \& Root, 1994; Linney, 1995; Hoffmann, 2000; PATH, 2002).

However natural it may be to promote visuals in educating low-literate audiences, it is all the more difficult to determine which visuals should be used for which purposes, and when and why they are better. Studies on the use of visuals by low-literate audiences are largely based on best practices or on case studies, resulting in surveys of anecdotal problems with guidelines for using visuals in a low-literate context (e.g. Hoffmann, 2000). For example, distracting details can cause the unskilled viewer to miss the central focus of the visual, or to focus on incorrect or insignificant details (Ausburn \& Ausburn, 1983; National Cancer Institute, 1994; Linney, 1995; Doak et al., 1996; Program for Appropriate Technology in Health [PATH], 2002). Visuals can be misunderstood due to differences in culture and background (Tomaselli \& Tomaselli, 1984; TrippReimer \& Afifi, 1989; Cornwall, 1992; Bradley, 1995; Doak et al., 1996). They can also be too difficult due to graphical conventions, such as depth perspective, speech balloons and metaphoric or mathematical symbols (Colle \& Glass, 1986; Bradley, 1995; Linney, 1995; Doak et al., 1996; Hoffmann, 2000; PATH, 2002; Arbuckle, 2004). Finally, visuals are poorly equipped to express animation (moving elements, ctions, event sequences) as well as modalities and speech acts (can, must, should, etc.) (Colle \& Glass, 1986; Linney, 1995; Hoffmann, 2000; PATH, 2002; Arbuckle, 2004).

A systematic and reliable account of the effect of visuals in a low-literate health context is lacking, however, due to a large number of complexities associated with this type of research. First, there is a striking absence of a sound theory on the relationship between the characteristics of visuals on the one hand and the processing of visuals by low-literate audiences on the other. There is sound empirical work in the field of spatial cognition on how humans derive cognitively adequate meaning from analogical (as opposed to symbolic or arbitrary) sign systems, such as graphics and visuals (e.g. Gattis, 2001; Tversky, 2001; Tversky, 2002), but hardly any work in this area is applied to low-literate audiences. Likewise, educational psychologists have a long tradition of research on using multiple representations for learning (i.e. text plus visuals, auditory cues and animation; for an update, see Mayer, 2005), but again the application range hardly ever transcends the boundaries of formal literacy. Moreover, there is a lack of standard language to analyse and talk about the meaning of visuals, especially to chart and categorise the relevant types of 'real-world' distortions in visuals, the different degrees of abstractness, and the nearly endless complexities and subtleties exhibited in visuals.

Second, health messages are often personal and the subjects may be taboo, which makes any study of health-related communication sensitive and complex. The real-life character of visual communication makes it all the more delicate. Additionally, the personal character of health communication also evokes numerous reactions from readers or viewers. Health messages affect not only attention or understanding but have also a large number of hardly graspable, affective, behavioural and attitudinal effects which determine health behaviour (see Perloff, 2001; Fishbein \& Yzer, 2003). 
Third, studying communication in a low-literate context is challenging in terms of finding adequate procedures. Data collection methods (such as questionnaires) or methods in which visuals are evaluated, explained or compared do not easily match the low level of literacy of the target group. In addition, researchers should be aware that differences in literacy level also accompany differences in culture, attitudes and values, which again complicates the collection of reliable and generalisable data.

In this article, we explore the relationship between levels of complexity and abstractness in visuals, and levels of literacy regarding target groups. We discuss the results of a study in which low-literate and literate respondents were presented with a selection of visuals used in AIDS education materials in South Africa. In structured interviews, they had to identify the different elements represented in the visual as well as the intended message of the visual, and they were asked about specific complexities and abstractions displayed in the visuals. The results show that differences in understanding visuals increased between literate and low-literate individuals as the level of visual abstraction increased. Whereas there was hardly any difference in the recognition of simple analogical elements, differences increased significantly when the intended meaning of the visual was dependent on abstractions or arbitrary visual conventions. Before going into the details of the study, we define the notion of visual complexity in terms of different degrees of analogy or abstractness.

\section{What makes visuals difficult for low-literate audiences?}

In this study, we focus on a selection of visuals representing instructions, warnings and recommendations about preventing HIV infection or living with HIV. The visuals represent messages and styles that can often be found in brochures and other education materials about HIV and AIDS. However common these visuals are in HIV-education materials, they actually communicate messages for which visuals are not ideally suited. They mostly represent deontic modalities (what people should do to prevent HIV or to live with HIV as healthily as possible). This implies two types of meaning that are not compatible with the potential of the visual medium: static visuals cannot express people's actions directly, and they cannot directly express the difference between deontic and epistemic states of mind, for example the difference between what is, as opposed to what can or should be. This results in visuals that are complex combinations of analogical and symbolic elements, and that require recognition and understanding at different levels. Although the pictures appear to be simple, they impose heavy cognitive load on the viewers, who have to recognise individual elements and attribute relevant roles to them in the depicted scene or situation. Viewers also have to recognise and understand abstract elements and conventions suggesting meaning aspects that cannot be visualised directly (such as action and states of mind); and they have to combine all this to derive the ultimate message.

These levels of complexity can be illustrated in visual 1 (v1) (see Addendum) used in the experiment. On the basic level, this visual consists of a number of elements: it represents two clusters of human beings: a large and a small female, and a male, a female and a baby. A second level consists of deriving relationships between these elements. Generic cultural knowledge and the interpretation of facial expressions are needed to interpret a scene in which a mother (or other adult female) is talking to a younger female, probably her daughter. The proximity, similar size and closed shape suggest that the three small humans belong together, for example as a family. Less simple is the relationship between the two human beings in the main picture and the three people in the enclosed picture (labelled a 'thought balloon', 'thought bubble' or 'callout' in media jargon). Here, again, different complexity levels can be distinguished. Viewers should realise the difference between the two humans in the centre of the visual and the three small humans somewhat in the background. This is a graphical convention that requires visual literacy, but there is a clear analogy with the way we perceive the world, particularly how we experience near (larger) and far (smaller) things in our environment. More abstract is the representation of the thoughts of human beings within a 'balloon' above the head of the thinker and linked by smaller balloons decreasing in size, as used in v1. Again this is a graphical 
convention, but this time with only a faint analogy, i.e. the cognitively natural association between thoughts (the higher-order things of the head) and the thought balloon's location in the upper part of the visual, above the head of one of the humans.2 Finally, in the balloon itself the mathematical signs '+' and ' $=$ ' are used, which do not have any analogical relic and rely completely on the knowledge of arbitrary symbols in mathematics. In sum, the health message expressed in this visual, namely that mothers should discuss the facts of life with their daughters, is the result of a complicated interplay of visual elements and conventions, ranging from highly analogous (i.e. the representation of objects/humans) to highly abstract (i.e. the mathematical symbols), with different degrees of analogy and abstractness in between.

The question we want to address in this article is how low-literate viewers understand the different levels of analogy and abstractness in such visuals. The answer will be sought in comparing the responses of low-literate respondents with those of literates. We will answer the question whether there is an equal difference in understanding on all levels, or whether the difference in understanding increases as the level of abstractness increases. Furthermore, we want to know how differently literate and low-literate viewers interpret the degrees of abstract analogy in visuals. As a general expectation, we assume that it is easier to understand pictures than text because visual elements enable viewers to derive meaning on the basis of the analogy with their own bodily experiences, as well as with objects, actions and goals; which in turn is congruent with the idea advocated in embodiment theory, that human beings always create meaning on the basis of their sensory experiences, guided by their actions and goals (see Barsalou, 1999; Glenberg, 2002; Zwaan \& Madden, 2005).

\section{Methods}

We presented two groups of respondents, one comprising low-literate respondents and the other comprising literate respondents, with the same selection of visuals. In structured interviews, using the same schedule, we asked the two groups the same questions about each visual. The collected data was partially coded and statistically analysed using SPSS, to compare the two groups quantitatively.

\section{Participants}

Since the concept of literacy is gradable, rather than absolute, we used as a reasonable criterion a maximum of seven years of formal schooling for low-literates and a minimum of nine years of schooling for literates. The literacy levels of the respondents were determined on the basis of self-reports regarding years of formal schooling. South African law regulates that learners who have passed Grade 9 may leave school and start tertiary training; persons with fewer than nine years of schooling are regarded as only marginally literate in terms of the categories defined by Project Literacy (2004).

One group consisted of 30 low-literate participants who are mother-tongue speakers of one of eight African languages, and were age 22-55 (mean 43.3 years). Twenty-five were females and five were males, with an average of 3.7 years of formal schooling. The other group comprised 24 literate participants, mother-tongue speakers of one of 11 African languages, age 20-52 (mean 32.7 years). Seventeen were females and seven were males, with an average of 12.6 years of formal schooling. The sampling method was both convenient and purposive, as the researchers relied on personal acquaintances to identify and recruit respondents who satisfied the literacy requirements. This explains the overall gender imbalance as well as the difference in the mean age of the two groups. The researchers interviewed all the respondents individually. The first author interviewed low-literate respondents in Constantia Park and Waterkloof Glen in Pretoria as well as in KwaMhlanga, and the third author interviewed literate respondents in Pretoria Central, Menlo Park, Lynnwood and Hatfield.

\section{Materials}


The materials comprised a compilation of fourteen visuals (addendum: v1-v14) taken from various public information documents on HIV/AIDS that had been collected from educational and public healthcare facilities (clinics, hospitals, schools) in and around Pretoria during the period 2000-2004. The visuals were scanned and arranged in a narrative sequence representing the story of HIV, which provided participants with a basic interpretation frame, in the absence of any other written information. We realised that these materials lacked ecological validity in the sense that the document used for testing was an artificial compilation.

On the other hand it was the only way that we could test examples of a variety of potentially problematic visuals that did actually occur in materials widely available to low-literate South Africans.

The narrative sequence was as follows:

Preventing AIDS

1. Mothers should discuss sex and pregnancy with their daughters.

2. Fathers should talk to their sons about using protection (condoms).

3. Young couples should postpone sexual debut.

4. Young couples should negotiate the use of condoms.

5. A pregnant woman and her partner should consider the fact that their baby may be HIVpositive if the mother is seropositive.

6. Everyone should go for voluntary counseling and testing (VCT).

Living and staying healthy with AIDS

7. People who have heard that they are HIV-positive should go to a counsellor.

8. You should exercise regularly.

9. You should rest and relax enough.

10. You should not eat junk food.

11. You should eat healthy food.

12. You should not drink alcohol.

13. You should not smoke.

14. You should take your ARV medicines on schedule.

As the addendum shows, all the visuals were drawings rendered in different styles: three blackand-white semirealistic line drawings, one silhouette, two coloured cartoonstyle drawings, and eight semi-realistic coloured line drawings with varying degrees of background noise.

\section{Data collection}

The data were collected via structured interviews. The general procedure was to start each interview by introducing the interviewer, and asking about the preferred language for the interview. Interviewees were informed that their responses would be tape-recorded anonymously, that their participation was voluntary, and that they were entitled to withdraw their participation at any stage during the research process. Each respondent was asked verbally for his/her consent to use the collected data, and to proceed with the interview. Only one respondent in the experimental (low-literate) group preferred not to continue with the interview.

After the introduction, the respondents were briefed on the purpose of the research, namely to assist the researchers in finding out which of the visuals should be included in health-education materials distributed at clinics. We assumed that low-literate participants would have less general knowledge about preventing HIV and living with HIV than did literate participants. Therefore, in the low-literate condition the structured interviews were preceded by a semi-structured briefing (without visual support) on the topic of HIV, according to a schedule covering sexual debut, prevention of HIV, and coping with HIV illness. The researcher asked questions, confirmed correct answers, and provided information when the respondent did not know an answer or held erroneous beliefs, in order to create sufficient contextual knowledge for the interpretation of the visuals. Respondents were invited to ask questions, and to comment on any of the issues raised. In the literate condition, this phase was skipped. 
Subsequently, participants were asked sociodemographic questions (age, occupation, years of formal schooling, first-language), followed by the actual experimental interview. In both conditions the interviewer presented the respondent with the visuals one by one and asked questions in a semi-structured fashion about (i) the recognition of the objects, (ii) the relationship between the objects, and (iii) the message of the visual. Respondents were invited to comment on particular aspects of the visual if they had not referred to them in their initial response.

The first 10 low-literate respondents were interviewed in the township of KwaMhlanga by the first author. The interviews were conducted at the house of one of the participants. The preinterview briefing on HIV/AIDS took the format of a group discussion. Since the mother tongue of all the attendees was Ndebele, but the preferred language was English, both languages were used, with interpretation between them by a fluent speaker of both. The experimental interviews took place individually. After completing two interviews, the interviewer realised that the respondents were much more fluent in Afrikaans than in English. Therefore, all the subsequent interviews took place in Afrikaans, as it saved time, and produced direct and reliable answers. The interpreter's assistance was sought whenever a word or phrase in either Afrikaans or Ndebele was not understood by one of the participants.

Twenty more low-literate respondents were interviewed in Constantia Park and Waterkloof Glen. The interviews took place by prior arrangement with the home owner, and were conducted individually. Pre-interview briefings were also done individually. The interviews were conducted in Afrikaans for pragmatic reasons and because proficiency in English in the age group 35+ remains generally poor (Afrikaans is still the dominant lingua franca between employers and employees in the eastern suburbs of Pretoria; many of these workers have been in domestic service as nannies, cleaners, cooks and gardeners for 20 years or more, and have acquired the spoken version of Afrikaans at a fairly sophisticated level). All the interviews were recorded, transcribed and translated into English by the first author. The interviews with the 24 literate respondents were conducted individually in English by the third author.

\section{Coding and analysis of data}

The quantitative analysis of the data was structured on the basis of the following questions, reflecting different levels of understanding:

- Does the respondent recognise the elements? That is, name and function of the analogous elements (humans and objects); name and function of the abstractanalogous elements (metaphors); and, name and function of abstract elements (symbols).

- Is the respondent able to verbalise the message of the visuals?

- Is the respondent able to explain the role of the abstract elements in relation to the intended message?

For a few elements in the visuals, there are no quantitative results available due to the fact that the researchers did not ask a question verifying the participant's recognition of it (e.g. the ball in v8, or the couch in v9) or because they did not ask about it systematically (e.g. the condom in v4). So, we only compared the recognition of the items for which the data was complete for both groups.

Additional fine-grained qualitative analyses were used to refine the quantitative results.

\section{Results}

\section{Recognition of elements}

Table 1 shows the mean number of elements recognised per participant. A two-way analysis of variance (ANOVA) with abstraction level (humans, objects, abstract objects) as a within-subjects variable, and literacy level (literate or lowliterate) as a between-subjects variable, shows a main effect of literacy level $(F=39,36, p<0.001)$. Hence, low-literate respondents recognised fewer 
elements than literate respondents. The analysis also shows a main effect of abstraction level $(F$ $=34,94(2,51), p<0.001)$, as well as an interaction effect of abstraction level by literacy level $(F=$ $38,93, p<0.001)$. Pairwise comparisons, using a t-test for independent samples, shows that the two literacy groups differed in the recognition of objects and abstract objects $(\mathrm{t}(49,71)=-5.2, \mathrm{P}<$ 0.001 and $t(42,89)=-7.25, p<0.001$, respectively), but not in the recognition of human beings $(p$ $=$ n.s.).

These results are consistent with the ideas put forward in the introduction. First, for literate and low-literate respondents, the recognition level decreased as the elements became less familiar and less related to their own embodied experiences: humans were more easily recognized than non-human objects and abstract objects, respectively. Second, the difference between literate and low-literate participants increased as the elements became more abstract, and less embodied.

\section{Human beings}

Both literate and low-literate respondents had little difficulty recognising the human beings in the visuals, irrespective of art style. Only a few participants misinterpreted the gender of the person (e.g. referring to a woman and a man in v2). The groups were equally successful in attributing relevant roles to the humans (mother, father, lover, couple, etc.), although some illustrations of humans were problematic, especially when the scene represented was less familiar. For example, $v 7$ was often seen as a man-wife scene instead of a patient-counselor scene. Likewise, v14 often posed problems due to the uncertain role of the two humans in the background. In v1-v5, the majority of the respondents attributed close family ties between the human beings (i.e. v1 mother-daughter, v2 father-son, v3 and v4 young couple, v5 husbandwife). However, sporadically, more distant relatives and even non-familial relationships were mentioned, such as older and younger sister, older and younger brother, other family members or counselors.

\section{Analogous objects}

A number of the analogous objects, such as a bed, the food items, a bottle, a cigarette and an ash tray, are everyday occurrences in the lives of literate as well as low-literate people, and the two groups showed little or no differences in recognising them. Likewise, there was no difference in recognition of the condom, which may be attributed to the participants' daily experience, but also to the prominence of condoms in HIV information sources, such as billboards, which probably increases the iconic recognition of condoms even for people not using them regularly.

Recognition of the (less familiar) objects belonging to the medical domain show a larger variation. In v6, the syringe was recognised by all respondents, while the blood tube was recognised better by the literate respondents (54.2\% vs. $36.7 \%)$, but resulted in a number of misinterpretations among the low-literates (such as pills, a 'man's thing', vaccine, 'things you put on your lips', and a condom). Finally, the consent form in v6 was recognised exclusively by the literate respondents $(66.7 \%)$, which is of course because of the written prompt on the illustrated sheet of paper. Likewise, the pills in v14 were recognised better by the literate respondents (100\% vs. $76.7 \%$ ).

In sum, within the class of analogous objects, there were recognition differences between familiar and less familiar objects: for all respondents, familiar objects were easier to recognise, but again, the differences between the literate and low-literate respondents increased as the unfamiliarity of the objects increased. This could be caused by systematic differences in familiarity and practical experience with medical objects in the two groups (which we did not measure).

\section{Abstract objects \\ The most significant differences in recognition were found with abstract objects. All the respondents struggled with the recognition of such objects, but the low-literate individuals demonstrated markedly more difficulty with this category than the literate ones. Apparently, a low level of formal education blocks the development of a vocabulary for abstract visuals.}


Table 1: Mean number of recognised elements per respondent for visual elements on three abstraction levels (humans, analogous objects and abstract objects) as a function of literacy (literate vs. low-literate individuals) (see visuals 1-14 in addendum)

\begin{tabular}{lll}
\hline Abstraction level: & Literates & $\begin{array}{l}\text { Low- } \\
\text { literates }\end{array}$ \\
\hline $\begin{array}{l}\text { Number of humans recognised }(\mathrm{n}=10)(10 \text { duos, trios or } \\
\text { individuals in nine visuals) }\end{array}$ & 8.83 & 9.07 \\
$\begin{array}{l}\text { Number of analogous objects recognised }(\mathrm{n}=10)(\text { see v2 condom, } \\
\text { v3 bed, v6 syringe, v6 blood tube, v6 consent form, v10 good food, }\end{array}$ & 9.13 & 7.77 \\
v11 bad food, v12 alcohol bottle, v13 ash tray and cigarette, v14 & & \\
pills) & & \\
$\begin{array}{l}\text { Number of abstract objects recognised }(\mathrm{n}=11)(\mathrm{v} 1 \text { mathematical } \\
\text { symbols, } \mathrm{v} 1 \text { thought balloon, v2 speech balloon, v3prohibition }\end{array}$ & 8.13 & 4.57 \\
$\begin{array}{l}\text { cross, v4 hearts, v5 AIDS monster, v8 action lines, v10 prohibition } \\
\text { cross, v11 V-tick, v12 prohibition cross, v13 prohibition cross, v14 } \\
\text { clock as icon for 'taking medicines on time') }\end{array}$ & \\
\hline
\end{tabular}

The class of abstract objects is not monolithic and reflects different types and grades of abstractness. A more fine-grained analysis shows a fairly systematic relationship between grades of abstractness and recognition success, along the lines suggested in the introduction. In Table 2, five classes of abstractness are distinguished, which are largely ranked according to the recognition success of the low-literate respondents.

\section{Prohibition cross}

A number of abstract objects have analogical roots and correlates, based on embodied experiences. A clear example is the use of a cross to express the modality of prohibition. Despite some misinterpretations (e.g. hospital sign), a fair percentage of respondents interpreted the cross correctly. A major reason may be that the cross reminds of the bodily experience of blocking someone's way by using two crossed objects (e.g. spears), which is a logicomathematical sign, and is also used in various cultures.

However, the success of the cross is different in the four visuals, most probably caused by the complexity of the message as a whole, rather than by the difference in design. The prohibition cross is easier to interpret in combination with objects often associated with prohibition (such as cigarettes and alcohol). The combination with food (in this case unhealthy food) is less clear, and the most complex case is $\mathrm{v} 3$, in which the cross is applied to a bed, which is only prohibited in relation to the complex message of the whole visual.

\section{Metaphors}

Another type of analogy is displayed in the metaphorical use of the clock, the hearts, and the monster. For most respondents, the clock in v14 correctly stands for the time of the event expressed in the visual ( $91.7 \%$ literates vs. $73.3 \%$ low-literates). This results in the interpretation that one should take medicines at two o'clock. However, the real interpretation is more abstract and generic, meaning that medicines have to be taken according to a strict schedule, for example 'every day at two o'clock'. This generic interpretation implies a further level of abstractness, which is apparently more difficult for low-literates (83.3\% vs. $43.3 \%)$

The other two metaphors (heart is love in v4, and monster is dangerous/AIDS in v5) require an interpretation that is less natural and general. The use of red hearts in v4 as a metaphor of love takes for granted that the romantic meaning of red hearts has been popularised by mass media 
such as in cartoons and greeting cards. The responses of the low-literate group could be interpreted as a lack of exposure to print materials in general, but also the score of the literate respondents is relatively low. Another possible explanation for the low score is the influence of language-supported cultural meanings. Five low-literate respondents answered that the boy is 'thinking with the heart', and when asked for an explanation they said he was worrying or ruminating. Specialists of a number of African languages were consulted to find out whether these languages contained a semi-idiomatic expression that would be translated directly as 'thinking with the heart', but meaning 'to worry'. According to S. Mahlangu (pers. comm.), a lexicographic practitioner at the University of Pretoria who speaks several African languages, the Sepedi expression o bolela ka pelo and the Zulu expression ukhuluma ngenhliziyo can be literally translated as 'to talk with the heart', but actually mean 'to worry'. Although the number of respondents who assigned this meaning was relatively small, their responses indicated that the use of cultural metaphors is precarious in a multicultural context such as South Africa.

The monster in v5 was seldom (16\%) interpreted as HIV or AIDS, both by low-literates and literates. More often, respondents related the monster to a more generic interpretation of sickness (germ, bacterium, virus) or danger. According to Ms Mahlangu (personal conversation) the African languages do not have a unified way of metaphorising HIV or AIDS. In Ndebele, for instance, AIDS is viewed as a big, prehistoric animal, which has been lexicalised as isilwani. In Ms Mahlangu's opinion it would be extremely difficult to use one single metaphorical visual to symbolise the meaning of HIV or AIDS for speakers of all the African languages. Mayeaux et al. (1996, p. 205) advise that "to be effective with patients whose literacy skills are low, patient education materials should be short and simple, contain culturally sensitive graphics and encourage desired behaviour". Culturally sensitive graphics would, for instance, exclude visuals portraying taboo elements, and unfamiliar pictorial metaphors. Although only two culturedependent metaphorical visuals were included in the testing materials, the responses indicated that this kind of visual is problematic.

Table 2: Percentage of abstract objects recognised by literate and low-literate respondents Literates Low-literates

\begin{tabular}{lll}
\hline & Literates & Low-literates \\
\hline Modality signal (prohibition cross) & & \\
Do not drink alcohol (v12) & 91.7 & 90 \\
Do not smoke (v13) & 95.8 & 90 \\
Do not eat this food (v10) & 75 & 43.3 \\
Do not sleep with your partner (v3) & 87.5 & 30 \\
Metaphors & & \\
Clock stands for the time of the event (v14) & 91.7 & 73.3 \\
Clock stands for taking pills in a timely manner (v14) & 83.3 & 43.3 \\
Hearts stands for love (v4) & 54.2 & 30 \\
Monster stands for danger or HIV/AIDS (v5) & 66.7 & 36.7 \\
Suggestion of action & & 16.7 \\
Action lines (v8) & 50 & 43.3 \\
Symbols & & 3.3 \\
V-tick (v11) & 66.7 & \\
Mathematical symbol (+,=) (v1) & 66.7 & 3.3 \\
Speech and thought suggestions & & 3.3 \\
Speech balloon (v3) & 62.5 & \\
Thought balloon (v2) & 58.3 & \\
\hline
\end{tabular}

Indicators of action

In one case, the visual expressed action: the curved line in v8 expressing the movement of a leg. Although most respondents correctly interpreted the action depicted, only a small portion $(50 \%$ vs. $16.7 \%$ ) was able to interpret the line correctly in relation to this action.

\section{Symbols}


In a few cases, symbols were used without any residue of analogy (e.g. the mathematical symbols in $\mathrm{v} 1$ and the $\mathrm{V}$-tick in $\mathrm{v} 11$ ). The mathematical symbols presented major problems for the low-literate group. Only one respondent was able to name the symbols ' + ' and ' $=$ ' in the thought balloon, and to give an acceptable interpretation of the content. A confounding factor might have been that the symbols in the balloon are not used in their primary logicomathematical senses. The symbol ' + ' is used as a synonym for unite rather than for the sum of, and the symbol '=' means is the product of, rather than equals. Another possible reason why the symbol '+' was not interpreted as a mathematical symbol is that in the context of health education this symbol is often used to represent healthcare facilities. Four of the low-literate respondents identified the ' + ' as a sign for a hospital or clinic.

The V-tick is interpreted correctly more often, despite the arbitrary nature of the symbol. One possible explanation may be that the positioning of this visual in the picture sequence helped considerably in interpreting the symbol. It is probably a logical deduction that a picture displaying unhealthy food and a prohibiting cross should be followed by a picture showing healthy food. In addition, the colour coding (red vs. green, which is analogous to traffic lights) may have facilitated the correct interpretation.

\section{Indicators of speech and thought}

Low-literate respondents scored extremely low on understanding the speech and thought balloons in v1 and v2. Part of the problem may have been that second-language speakers of English would not know the terms for these shapes. In some cases, respondents derived other natural meanings from the closed shapes. For example, five respondents interpreted the thought balloon in v1 as a sign of 'togetherness' regarding the human beings enclosed in it. This reflects a general cognitive preference to interpret closed lines (circles) as containers (Tversky, 2002).

Somewhat less dramatic was the difference in the interpretation of the visuals representing human communicative or cognitive activities. Table 3 shows the percentage of literate and lowliterate respondents who used a verb of cognition (such as think or understand) to explain what is happening in the visuals using a thought balloon (v1, v3, v5), or a verb of 'saying' (such as say, talk, tell) to explain the visuals containing a speech balloon (v2 and v4). Again, there was a substantial difference between the two groups. Moreover, there was a difference between the respondents' use of verbs of 'thinking' and verbs of 'saying'. A plausible explanation is that the act of speaking can be supported by analogical embodied visual cues, in particular the parted lips of the human beings; this cue is more marked in v2 than in v4, which may explain the better recognition of v2. The expressive power of these facial expressions is further demonstrated by the fact that in responding to $v 1$, the respondents used significantly more verbs of saying (congruent with the facial expression of the mother) than verbs of thinking (congruent with the thought balloon) (literates: $75 \%$ vs. $54.2 \%$; low-literates: $46.7 \%$ vs. $10 \%$ ).

\section{Understanding the basic message of the visuals}

Apart from detailed questions about different types of elements in the visuals, the respondents were asked what they thought the message of each visual was. The visuals should somehow be understood as generic advice or a recommendation to act wisely or refrain from doing risky or unhealthy things, congruent with the story of HIV. This means that respondents had to interpret the visuals not so much as simply showing familiar scenes or facts of life, but rather as prescriptions of what they should do or refrain from doing. The problem is that this basic intention has no direct correlate in the visuals. 'Negative' advice (i.e. the advice to refrain from doing something or behaving in a certain way) can be expressed indirectly by using an abstract entity with an analogical residue (like the prohibition cross). However, 'positive' advice cannot be shown directly, but only indirectly by showing an exemplary scene of the intended action or behaviour, or by making use of a V-tick (as in v11 promoting healthy eating). Respondents must transform this neutral description (e.g. a mother talks to her daughter about the facts of life) into an advice or ecommendation (e.g. a mother should/must talk to her daughter). The ultimate interpretation requires a full understanding of the range of analogical and abstract elements, as well as correct assessment of this knowledge in the context of the story of HIV.

The results show that the understanding of the basic intention of the visuals differs substantially between visuals and between literacy levels. Table 2 shows that a cross is a relatively successful 
tool to express prohibition, but at the same time that the familiarity of smoking and drinking, as well-known instances of unhealthy behaviour, helps respondents understand the prohibition. Also, Table 2 shows that the message of v14 was relatively easily captured. Apparently, the combination of the clock, the glass of water, the position of the woman's hand and the containers results in a fairly easy interpretation of the advice to take medicines on time (or 'exactly at two o'clock').

However, the other recommendations were captured less easily. The low-literate and the literate respondents generally understood that the person depicted is exercising in v8 or relaxing in v9, but very few generically interpreted the activity as something an HIV-positive person should do to stay healthy. Similarly, the respondents largely understood what was being depicted in v6 and $v 7$, but they hardly ever translated this content into advice to go for VCT or visit a counsellor.

The intentions in $v 1$ to $v 5$ are particularly complex, not only because a relatively high number of abstract elements are used, but also because respondents have to reason about the thoughts of others and about interpersonal behaviour, whereas the message in the other visuals can simply be applied to personal (their own) behaviour. Table 4 shows the proportions of respondents that interpreted the visuals as a kind of recommendation or action cue. The high recognition score for the condom in v2, together with the clear facial expressions (the father speaking and the son listening), and probably also the familiar and straightforward recommendation expressed, explains the high score. The other recommendations are less well understood. A large difference between literate and low-literate respondents occurred with v1 and v3 due to the crucial dependence on formal literacy (i.e. the mathematical symbols in $\mathrm{v} 1$, and the t-shirt slogan 'true love waits' in $\mathrm{v} 3$, which was quoted or rephrased by a number of literate respondents). Finally, the emotion of sadness expressed in v5 was captured easily by almost all the respondents presumably on the basis of the clearly negative facial expressions. However, the main message was not readily understood, due to a combination of complexities (i.e. understanding the HIV metaphor and the question mark, and the recognition of the woman's pregnancy); the higher score of the low-literate group can only be explained by the fact that they discussed the HIV story prior to the experiment.

Table 3: Percentage of literate and low-literate respondents using a verb of 'thinking' (such as think, understand, realise) or verb of 'saying' (such as say, talk, tell) to explain the visuals using a thought or speech balloon

\begin{tabular}{lll}
\hline & Literates & Low-literates \\
\hline Verbs of thinking & & \\
visual 1 & 54.2 & 10 \\
visual 2 & 37.5 & 3.3 \\
visual 3 & 29.2 & 13.3 \\
Verbs of saying & & \\
visual 1 & 79.2 & 66.7 \\
visual 2 & 66.7 & 36.7 \\
\hline
\end{tabular}

\section{Conclusions}

Consistent with previous research, we found that purely analogical items (human beings and analogous objects) pose relatively few interpretation problems across the literacy spectrum. Moreover, literate and low-literate respondents recognised human beings and familiar analogous objects equally successfully. The interpretation of abstract items was problematic for respondents at both literacy levels, but relatively more difficult for the low-literate respondents. People with little reading skill and limited exposure to written media experience major problems interpreting abstract picture conventions and symbols from systems of formal logic. Interpretation problems are compounded where cognitive load is high: for example, when the symbol legibility is poor, when the symbols form part of a complex visual, or when they occur in the background of a visual.

A more detailed analysis of the respondents' recognition of abstract items has shown a general correlation between grades of abstraction and interpretation success: 
- Purely symbolic or conventional abstract elements, such as speech and thought balloons, and purely mathematical symbols are often unrecognisable for low-literate individuals, simply because they do not have any analogical residue that can be used to trigger relevant meaning aspects of the visual.

- Metaphors are problematic when they require culturespecific knowledge that is not part of the shared knowledge base of the target audience (as with the HIV 'monster' in v5 or the red hearts in v4).

- Less culturally specific metaphors can be more useful, but the example of the clock in v14 shows that it is more difficult for low-literates to understand visuals in a generic way, as opposed to a specific way.

- Abstract elements with a clear analogical residue can be relatively successful in expressing abstract meaning.

For example, the cross is fairly successful in expressing prohibition.

- Importantly, the data suggest that the actions and mental states of human beings can be more successfully expressed by using bodily expressions that are familiar on the basis of daily experience than by applying literacy conventions. For example, the action of exercising or playing football in v8 is recognised solely on the basis of the posture of the body and not by interpreting the curved 'action' line, which is apparently not triggering the action. Similarly, the act of speaking is better evoked by adequate facial expressions than by speech balloons. Likewise, the mental state of humans can be expressed successfully by means of facial expressions (as in v4 and v5) and/or posture (see v7).

Table 4: Percentage of literates and low-literates understanding the recommendations depicted in visuals 1-5 (see addendum)

\begin{tabular}{lll}
\hline & Literates & Low-literates \\
\hline $\begin{array}{l}\text { Mothers should teach their daughters the facts of life } \\
\text { (v1) }\end{array}$ & 58.3 & 23.3 \\
$\begin{array}{l}\text { Fathers should talk about using protection } \\
\text { (condoms) (v2) }\end{array}$ & 79.2 & 60 \\
$\begin{array}{l}\text { Young couples should postpone sexual debut (v3) } \\
\begin{array}{l}\text { Young couples should negotiate the use of condoms } \\
\text { (v4) }\end{array}\end{array}$ & 58.3 & 16.7 \\
$\begin{array}{l}\text { A pregnant woman and her partner should worry } \\
\text { about their baby (v5) }\end{array}$ & 16.7 & 43.3 \\
\hline
\end{tabular}

\section{Limitations of the research}

The results discussed here should be interpreted with caution, due to limitations in the setup of the experiment. First, we do not claim that the visuals used in the experiment represent all possible types of interpretation complexity. Although we attempted to select visuals from existing HIV education materials on the basis of some kind of frequently occurring complexity, this selection procedure could not guarantee complete coverage of visual complexities in general or visual complexities in HIV-education visuals in particular. Moreover, the number of visuals had to be limited, because the experiment was cognitively demanding, especially for low-literate respondents. As a consequence, we did not include sufficient examples of any problematic type of complexity (e.g. indication of action). However, the results may enable us and other researchers to make a more justified selection in follow-up research.

Second, two different researchers conducted the interviews with the low-literate and the literate groups. Despite the use of the same interview schedule, their interview styles may have influenced the quality and the quantity of the responses.

Third, the interview language varied within as well as between the two groups. A more or less pragmatic (or convenience) approach was used: in the case of the low-literates some interviews were conducted in English and Ndebele, mediated by an interpreter; but the majority was in Afrikaans, without the mediation of an interpreter (all the responses were eventually transcribed in English). For the interviews with the literates, only English was used. 
Fourth, there were substantial differences in the two groups in terms of age and gender. Persons in the low-literate group tended to be older and probably less mobile than those in the literate group, conditions which probably also led to differences in exposure to visual media, and affected their ability to process complex visuals.

Finally, the low-literate respondents were presented with a more explicit interpretation frame for the visuals than the literate respondents, by discussing the story of HIV in a pre-interview briefing. Omitting this information would certainly have resulted in more dramatic differences. On the other hand, providing the literate respondents with the same explicit framework would have made the task too simple. However, despite the rationale, this decision may have biased some of the results.

\section{Suggestions to education material designers}

The results strongly suggest that HIV-education material designers should exploit the expressive power of the human body in constructing (abstract) meaning. All humans have comparable experiences with basic actions and bodily expressions associated with them. Therefore, facial expressions and body postures and positions are powerful in transferring complex messages. Moreover, the results strongly suggest using abstract elements 'with analogical roots', that is abstract elements that enable respondents to evoke relevant perceptual experiences (e.g. a cross as a blocking device). In using abstract elements, designers should reflect on the level of analogy. Pictorial metaphors, art styles that distort objects, complex pictures with partially symbolic content, as well as abstract symbols borrowed from written language should be omitted where possible.

What has become clear to us is that certain types of visuals may be problematic across a wide spectrum of literacy levels. As a result, we suggest that HIV-education use simple, low-literacylevel materials with clear or concrete graphics, regardless of audience reading skills. In the United States, patients in both high and low socioeconomic and reading-ability groups indicated that they prefer short, simple and colourful education materials (National Work Group on Literacy and Health [NWGLH], 1989). A study comparing a simplified 6th-grade reading-level brochure about polio (which combined simple text and line-drawings with captions) to a 10th-grade-level brochure) demonstrated that patients of all reading levels and all socio-economic levels preferred the shorter and simpler pamphlet; high-level readers understood both brochures equally well but took less time to read the shorter one, and apparently no one was offended by its simplicity.

Our concrete advice to the designers of health education materials distributed at state-funded clinics and hospitals in South Africa is to design these documents at a 5th-grade level (see NWGLH, 1989), and to include colourful, culturally relevant visuals as well as plenty of white space.

\section{Notes}

1 The term 'low-literate' is used in the conventional meaning of 'having a limited ability to read and write'. Although low-literacy often goes hand in hand with limited life experience and fewer encounters with visual media, these concepts cannot be equated. Grade-level remains a recognised criterion for (verbal) literacy, whereas there are no existing criteria for measuring life experience and visual exposure.

2 For the cognitive correspondence of these and other graphical conventions, see Tversky (2001) and the principles of gestalt perception.

Acknowledgements - The research was conducted as part of the EPIDASA project 'Improving the Effectiveness of AIDS Information Documents in South Africa' funded by SANPAD. We would like to thank Hans Hoeken and two anonymous referees for valuable comments on an earlier version of the paper.

The authors - Adelia Carstens is a Professor in the Unit for Academic Literacy at the University of Pretoria. She teaches professional writing and English for specific purposes, and her research 
focuses on the effectiveness of different visual and verbal formats for instructional materials, and genre-based approaches to teaching language.

Alfons Maes is Professor and head of the research group 'Communication and Cognition' in the Faculty of Arts at Tilburg University. His research and teaching concentrates on the use of different modalities (particularly, language and visuals) in creating meaning and transferring messages in different types of contexts.

Lilian Birir-Gangla is a Junior Lecturer in the Department of English at the University of the Free State. Her current research is on the effectiveness of different visual and verbal formats for instructional materials.

\section{References}

Arbuckle, K. (2004) The language of pictures: visual literacy and print materials for adult basic education and training. Language Matters 35(2), pp. 445-458.

Ausburn, F. \& Ausburn, J. (1983) Visual analysis skills among two populations in Papua New Guinea. Educational Communication and Technology 31(2), pp. 112-122.

Barsalou, L.W. (1999) Perceptual symbol systems. The Behavioural and Brain Sciences 22, pp. 577-609.

Bradley, S.M. (1995) How People Use Pictures - An Annotated Bibliography. London, International Institute for Environment and Development (IIED), and the British Council. Carstens, A. (2004) Tailoring print materials to match literacy levels - a challenge for document designers and practitioners in adult literacy. Language Matters 35(2), pp. 459-484.

Carstens, A. \& Snyman, M. (2003) How effective is the Department of Health's leaflet on HIV/AIDS counselling for low-literate South Africans? Tydskrif vir Nederlands en Afrikaans 10(1), pp. $112-136$.

Colle, R. \& Glass, S. (1986) Pictorial conventions in development communication in developing countries. Media in Education and Development, December 1986, pp. 159-162.

Cornwall, A. (1992) Body mapping in health. RRA Notes 16: Applications for Health (IIED), pp. 69-76.

Davis, T., Crouch, M.A., Wills, G., Miller, S. \& Abdehou, D.M. (1990) The gap between patient reading comprehension and the readability of patient education materials. The Journal of Family Practice 31(5), pp. 533-538.

Doak, C.C., Doak, L.G. \& Root, J.H. (1996) Teaching Patients with Low Literacy Skills.

Philadelphia, J.B. Lippincott Company. Fishbein, M. \& Yzer, M.C. (2003) Using theory to design effective health behaviour interventions. Communication Theory 13, pp. 164-183.

Gattis, M. (ed.) (2001) Spatial Schemas and Abstract Thought. Cambridge, Massachusetts, MIT Press.

Glenberg, A.M. (2002) The indexical hypothesis: meaning from language, world, and image. In: Allen, N. (ed.) Working with Words and Images: New Steps in an Old Dance. Westport, Connecticut, Greenwood Publishing Group, Inc. Grosse, N. \& Auffrey, C. (1989) Literacy and health status in developing countries. Annual Review of Public Health 10, pp. 281-297. Hoffmann, V. (2000) Picture Supported Communication in Africa. Weikersheim, Germany, Margraf Verlag. Linney, B. (1995) Pictures, People and Power. Hong Kong, MacMillan Education.

Mayeaux, J.R., Murphy, P.W., Arnold, C.A., Davis, T.C., Jackson, R.H. \& Sentell, T. (1996) Improving patient education with low literacy skills. American Family Physician 53(1), pp. 205211.

Mayer, R.E. (2005) The Cambridge Handbook of Multimedia Learning. Cambridge, Cambridge University Press. National Cancer Institute (1994) Clear and Simple. Developing effective print materials for low-literate readers. Available at: http://oc.nci.NCl.gov/services/Clear and Simple/HOME.htm [Accessed 15 October 2003]. National Work Group on Literacy and Health (NWGLH) (1989) Communication with patients who have limited literacy skills. Journal of Family Practice 46(2), pp. 168-176.

Perloff, R.M. (2001) Persuading People to Have Safer Sex: Applications of Social Science to the AIDS Crisis. Mahwah, New Jersey, Lawrence Erlbaum. 
Plimpton, S. \& Root, J. (1994) Materials and strategies that work in low-literacy health communication. Public Health Reports 109(1), pp. 86-92.

Program for Appropriate Technology in Health (PATH) (2002) Developing materials on HIVIAIDS/STIs for low-literate audiences. Research Triangle Park, North Carolina, Family Health International (FHI). Available at: http://www.fhi.org/en/HIVAIDS/

Publications/manualsguidebooks/lowliteracyquide.htm [Accessed 20 February 2004]. Project Literacy (2004) Education Statistics. Pretoria, South Africa. Available at: http://www.projectliteracy.org.za/education.htm [Accessed 22 September 2004].

Rudd, R.E., Moeykens, B.A. \& Colton, T.C. (1999) Health and Literacy. A Review of Medical and Public Health Literature. Annual Review of Adult Learning and Literacy. New York, Jossey-Bass. Available at: www.cete.org/acve/docs/pab00016.pdf [Accessed 20 February 2004].

Tomaselli, K.G. \& Tomaselli, R. (1984) Media graphics as an interventionist strategy. Information Design Journal 4(2), pp. 99-117.

Tripp-Reimer, T. \& Afifi, L.A. (1989) Cross-cultural perspectives on patient teaching. Nursing Clinics of North America 24(3), pp. 613-619.

Tversky, B. (2001) Spatial schemas in depictions. In: Gattis, M. (ed.) Spatial Schemas and Abstract Thought. Cambridge, Massachusetts, MIT Press.

Tversky, B. (2002) Some ways that graphics communicate. In: Allen, N. (ed.) Working with Words and Images: New Steps in an Old Dance. Westport, Connecticut, Greenwood Publishing Group, Inc. Zimmerman, M.L. (1982) Instructing through pictures: print materials for people who do not read. Information Design Journal 3(2), pp. 119-134.

Zwaan, R.A.C. \& Madden, J. (2005) Embodied sentence comprehension. In: Pecher, D. \& Zwaan, R.A. (eds.) Grounding Cognition. Cambridge, Cambridge University Press.

African Journal of AIDS Research 2006, 5(3): 221-232 231

Addendum: Pictorial narrative of HIV/AIDS shown to respondents in the study 

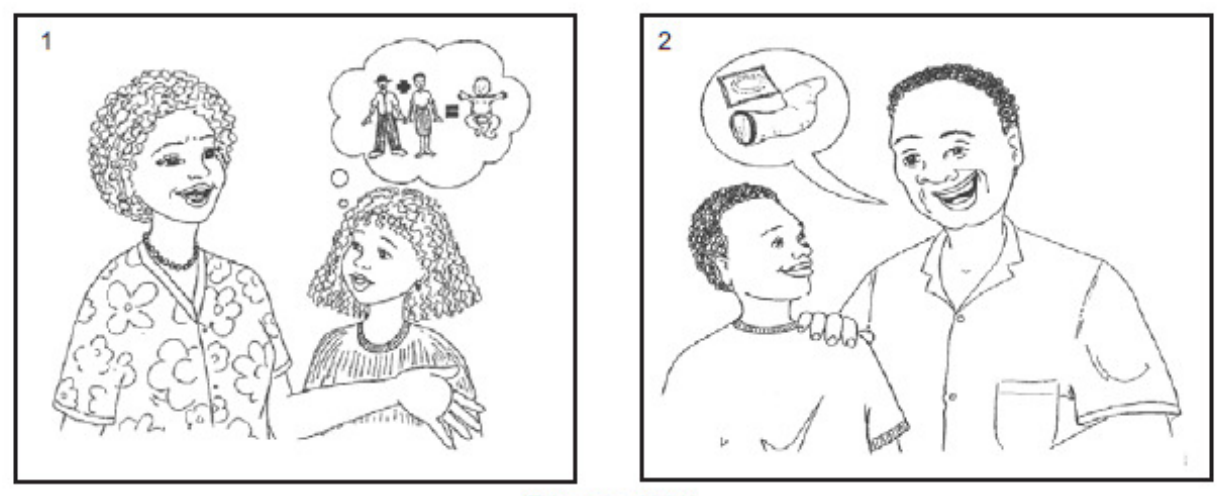

(Edwarcs, 2000)

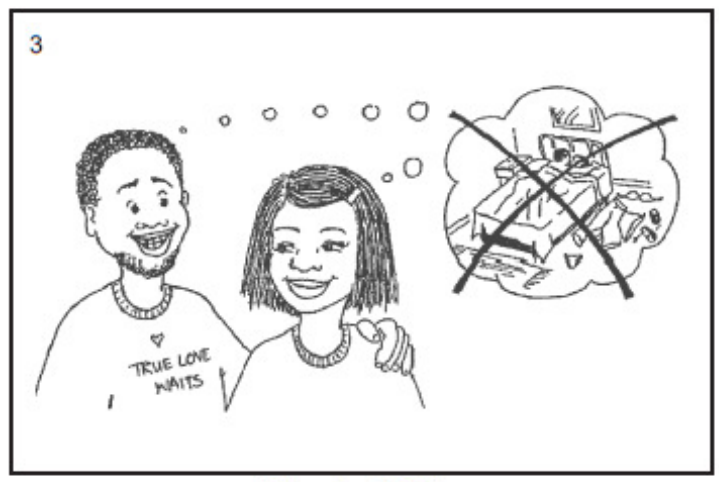

(Edwards, 2000)
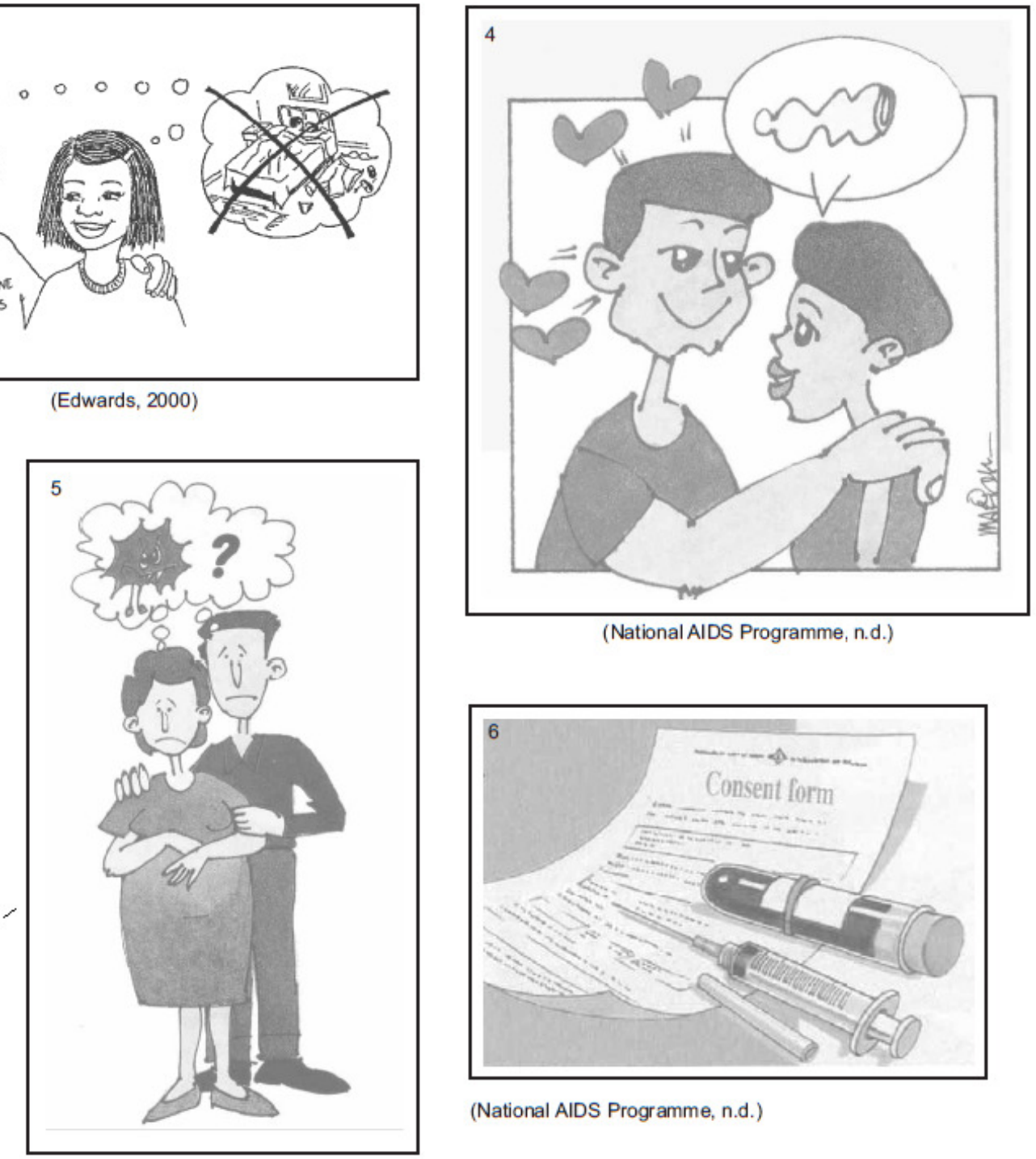

(National AIDS Programme, n.d.) 


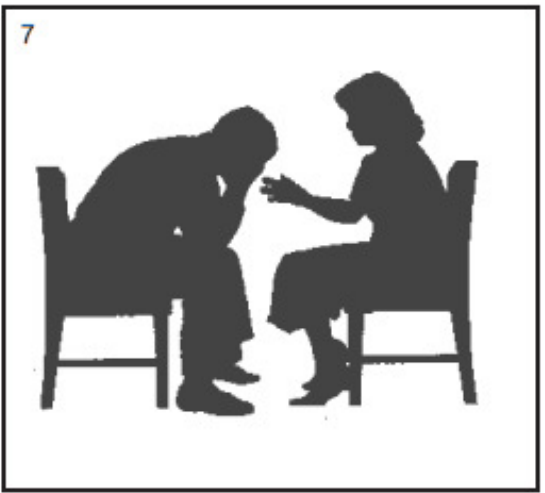

(Soul City/Khomanani, 2004)

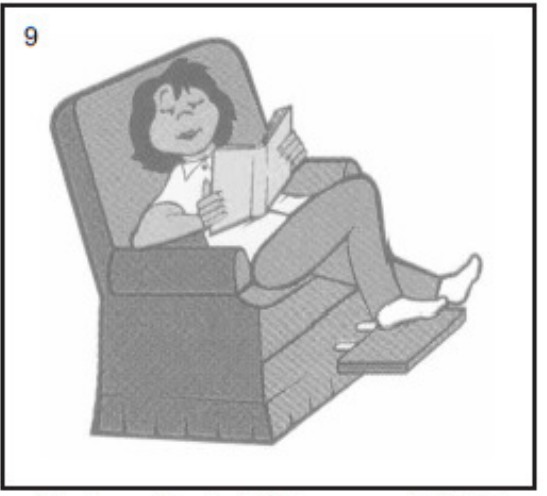

(Gauteng Provincial Government, 1999)

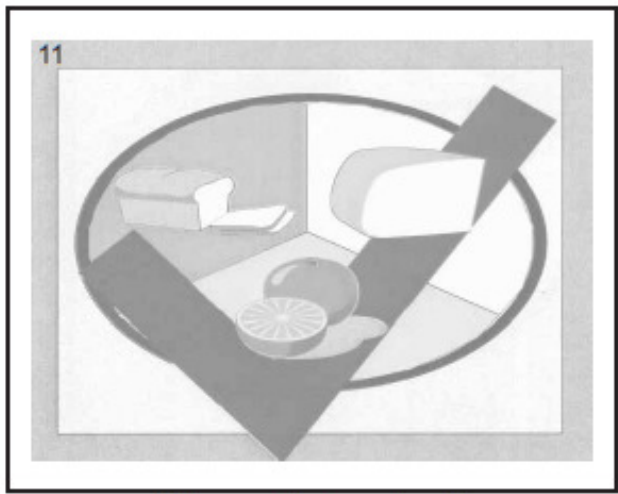

(Tshwane City Council, n.d.)

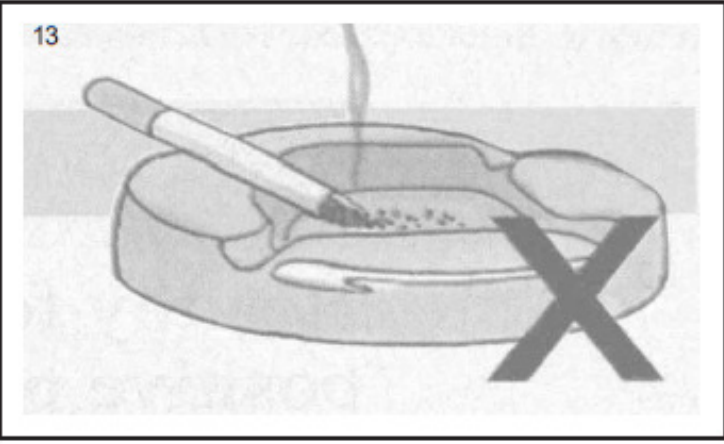

(Soul City/Khomanani, 2004)

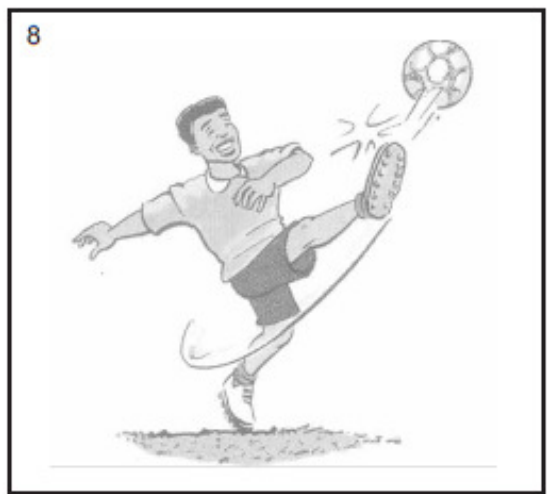

(Gauteng Provincial Government, 1999)

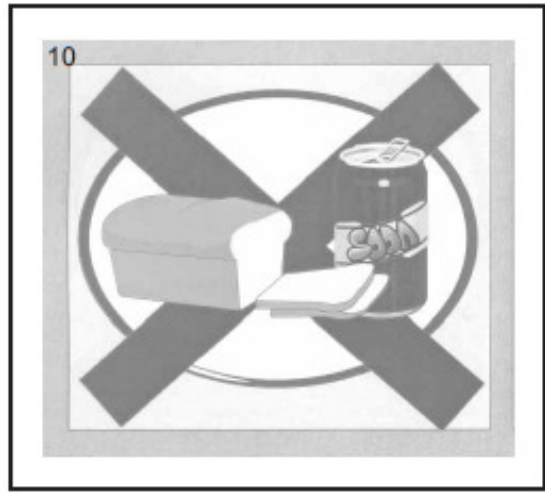

(Tshwane City Council, n.d.)

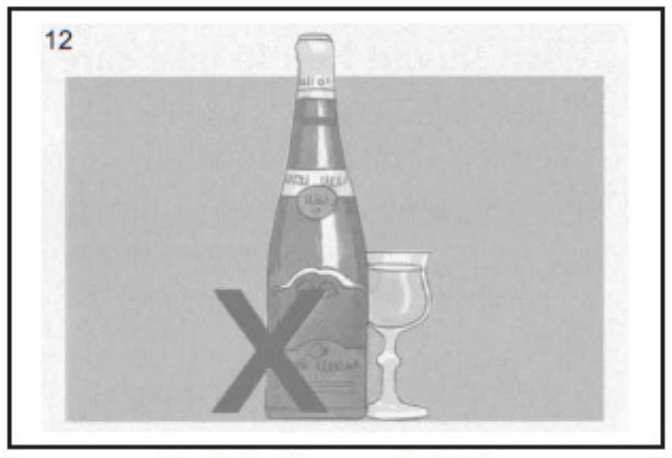

(Soul City/Khomanani, 2004)

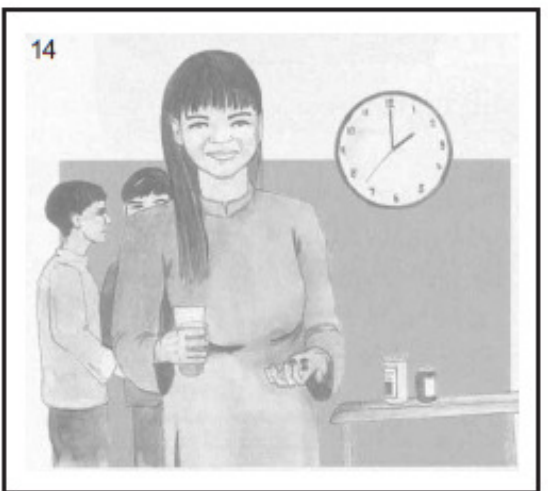

(Soul City/Khomanani, 2004) 